\title{
A “RECENSÃO A AENESIDEMUS" E A GÉNESE DA DOUTRINA DA CIÊNCIA DE FICHTE
}

\author{
Fernando Manuel Ferreira da Silva* \\ frndsilva@portugalmail.pt
}

RESUMO O presente ensaio aborda o periodo anterior às obras tidas como as diferentes reescrições da Doutrina da Ciência, de J. G. Fichte, e aí tenta não só perceber a origem da necessidade de um princípio da identidade, como ela surge aquando das primeiras ocorrências do mesmo, mas também discernir os primeiros passos de todo o problema da possibilidade (ou não) de um princípio absoluto de toda a filosofia, que sempre animaria a empresa. O foco em questão é a "Aenesidemus-Rezension», onde Fichte junta a sua voz ao aceso diálogo já anteriormente entabulado por K. L. Reinhold e G. E. Schulze, e, na necessidade de repensar o princípio da consciência do primeiro, e as críticas a este feitas pelo segundo, é trazido à convicção da necessidade de um novo princípio absoluto; mas onde, e é este o fulcro do presente ensaio, Fichte percebe a insuficiência filososófica do sistema reinholdiano como uma insuficiencia de linguagem, e portanto todo o problema como um problema que depende intimamente de uma apoditicidade linguística, e dai parte para a proposta de uma nova terminologia nacional, uma linguagem filosófica sistematicamente certa e inequívoca, à altura de um sistema filosófico regido por um princípio absoluto - um problema que viria a ocupar as cogitações de toda a geração de jovens pensadores em torno do professor de Jena.

Palavras-chave Fichte, Reinhold, Schulze, princípio, filosofia, linguagem.

* Centro de Filosofia da Universidade de Lisboa. Artigo recebido em 05/05/2015 e aprovado em 09/10/2015.

KRITERION, Belo Horizonte, nº 132, Dez./2015, p. 335-353 
ABSTRACT This essay approaches the period prior to the works considered as the different versions of the Doctrine of Science, by J. G. Fichte, and aims not only at discerning the origin of the need for a principle of identity, but also at retracing the first steps of the whole problem of the possibility of an absolute principle of all philosophy. The focus shall be the "AenesidemusRezension», where Fichte joins his voice to the heated argument previously struck by K. L. Reinhold and G. E. Schulze, and, urged to rethink Reinhold's principle of consciousness and the criticism raised by Schulze, is brought to believe the necessity for a new absolute principle; but where, and this is the fundamental idea of this essay, Fichte realizes the philosophical insufficiency of Reinhold's system as a language-related insufficiency, and therefore the whole problem as one intimately dependent on a linguistic apodicticity, and moves on to propose a new national terminology, a systematically certain and unequivocal philosophical language, which might meet the demands of a philosophical system ruled by an absolute principle - a problem which would soon be in the agenda of a whole generation of young idealists around the Professor of Jena.

Keywords Fichte, Reinhold, Schulze, principle, philosophy, language.

\section{Introdução}

De entre as diferentes versões a que, durante mais de quinze anos, Fichte viria a submeter a sua Doutrina da Ciência, quase todas ostentam esse nome e focam a questão de um princípio absoluto de toda a filosofia. "Über den Begriff”, o "Grundriß $\beta$ ", a Nova Methodo,${ }^{1}$ etc. são, dir-se-ia, reescrições anacronicamente dispostas de um mesmo sistema e de um mesmo problema, motivadas não só pela constante reelaboração do sistema no espírito do seu autor, mas também pela incompreensão a que o modo de expor de tal sistema, e o princípio que lhe presidia sempre se veriam expostos pelos seus leitores; ${ }^{2}$ e portanto, dir-se-ia, todas estas versões posteriores a 1793, imediatamente subsequentes à descoberta do princípio da identidade absoluta, são também a

1 „Ueber den Begriff der Wissenschaftslehre oder der sogenannten Philosophie, als Einladungsschrift zu seinen Vorlesungen über diese Wissenschaft” (1794); "Grundriß des Eigenthümlichen der Wissenschaftslehre in Rüksicht auf das theoretische Vermögen als Handschrift für seine Zuhörer" (1795); „Versuch einer neuen Darstellung der Wissenschaftslehre” (1797).

2 Vd., por exemplo, o prefácio a "Grundlage der gesammten Wissenschaftslehre” (1794). 
face mais visível e real da doutrina da ciência de Fichte, e constituem por certo o cerne teórico do pensar fichteano sobre este aspecto.

Mas outras versões há, as mais primordiais de todas - anteriores ou simultâneas a um princípio e de um sistema por esse nome -, que, embora focando este problema, não dão ainda por esse nome, e por isso tendem a passar mais despercebidas ao olhar do leitor e até de alguma crítica do autor. Não me refiro à "Zurückforderung der Denkfreiheit" (1793), ${ }^{3}$ nem ao "Beitrag zur Berichtigung" (1793). ${ }^{4}$ Refiro-me, isso sim, aos escritos que directamente testemunham a ocorrência primeira desse princípio absoluto em Fichte, e que por certo muito ajudam a elucidar os escritos a partir de 1794; eles que, aliás, podem e devem ser vistos como o germe do mesmo problema que, vindo de Reinhold e Kant, viria a ocupar a filosofia da época e a jovem geração idealista.

Assim, são dois os momentos da teoria de Fichte que destaco, e que de um modo singular nos podem ajudar a entender o processo de formação de um seu princípio da identidade absoluta, e a sua subsequente Doutrina da Ciência; e se digo singular, é porque, nestes, Fichte ora pugna ainda por um germe da sua Doutrina da Ciência, ora acabava de o obter, e dava-lhe voz pela primeira vez. ${ }^{5}$ São eles as esquecidas "Eigne Meditationen", ${ }^{6}$ um extenso conjunto de reflexões composto por Fichte entre Outubro de 1793 e Fevereiro de 1794; e a "Aenesidemus-Rezension", ${ }^{7}$ também composta durante o Inverno de 1793/94, esta produzida em resposta à Filosofia Elementar de Reinhold, e também à obra "Aenesidemus", de G. E. Schulze, de 1792: momentos precursores das referidas re-confecções da Doutrina da Ciência, ${ }^{8}$ e testemunhos

3 "Zurückforderung der Denkfreiheit von den Fürsten Europens, die sie bisher unterdrückten. Eine Rede, Heliopolis, im letzten Jahre der alten Finsterniß" (1793).

4 "Beitrag zur Berichtigung der Urtheile des Publikums über die französische Revolution".

5 São várias as versões sobre a data exacta em que Fichte alcançou o seu princípio. As cartas deste a Flatt e Stephani, entre Novembro e Dezembro de 1793, são por si sós esclarecedoras, mas a estas juntamos também palavras de Baggesen, datadas de 7 de Dezembro de 1793, e que situam essa descoberta nos primeiros dias de Dezembro, porventura nos últimos de Novembro desse ano (vd. Fuchs, Lauth, Schieche, 1978, 67-68).

6 "Eigne Meditationen über Elementar-Philosophie". In: FICHTE, J. G. Gesamtausgabe der Bayerischen Akademie der Wissenschaften. Hg. von Reinhard Lauth u. Hans Jakob, II 3, pp. 21-177, Stuttgart- Bad Cannstatt, 1965.

7 "Aenesidemus, oder über die Fundamente der von dem Hrn. Prof. Reinhold in Jena gelieferten ElementarPhilosophie. Nebst einer Vertheidigung des Skepticismus gegen die Anmaßungen der Vernunftkritik", in Fichte, 1971, Vol. I, pp.1-25.

8 Se menciono estes dois, não é porque eles sejam indelevelmente os mais importantes, e muito menos porque eles sejam os dois únicos momentos prenunciadores do subsequente edifício teórico de Fichte; mas apenas porque eles são aqueles que lhe são imediatamente antecedentes, e portanto aqueles que mais nitidamente dão a entender a premência do tema. A estes, porém, se poderia juntar um outro, que não só tão bem mereceria o epíteto de possível versão primordial de uma doutrina da ciência, como nele se prefigura aliás o problema de que viria a nascer toda a questão da doutrina da ciência. Refiro-me à obra "Kritik aller Offenbarung", de 1792, a qual, publicada a par de "Die Religion innerhalb der Grenzen der bloßen Vernunft", de Kant, e também aliada à crítica reinholdiana, suscitariam, cada qual à sua maneira, 
daquela que terá de ser considerada como a mais decisiva época do curso teórico de Fichte. ${ }^{9}$

Porque a ocasião não o permite, tratarei apenas um destes dois momentos: o decisivo cruzamento teórico entre Fichte, Reinhold e Schulze, na "Aenesidemus-Rezension".

Com a análise deste escrito, espera-se perceber o porquê da necessidade de uma doutrina da ciência; e uma vez alcançado este propósito, espera-se que ele nos possa ajudar a discernir alguns dos contornos iniciais daquela que sempre seria a questão principal para o Professor de Jena, e que viria a centrar os esforços de toda uma geração de filósofos à sua volta: a questão da possibilidade de um princípio absoluto da filosofia em geral, isto é, de uma filosofia por princípios, e uma total sistematização da filosofia.

Isto, traduzo-o sob a forma dos três objectivos concretos deste ensaio:

um conflito com a ortodoxia supernaturalista de Tübingen (Storr, Flatt ou Süßkind): um conflito entre religião e filosofia, ou a pretensa supremacia exegética de cada uma delas sobre a outra, que muito influenciaria a subsequente dimensão do problema (na procura de um princípio absoluto da filosofia, que aqui nos ocupará), e que decisivamente influenciaria todos os envolvidos, e não menos também Schelling, Hölderlin ou Hegel. Não que as duas obras citadas não tenham propósitos diferentes; a saber, Kant visa filtrar os textos do Evangelho que recaem no raio de análise da razão humana e, com isso, discernir quais as doutrinas do Cristianismo que têm ou não importância para a determinação da vontade - o que o leva a aceitar de facto a revelação, ou os milagres, mas a arrumá-los no compartimento daquelas manifestações que, não podendo ser negadas, não podem porém evidenciar causalidade, e por isso não seriam racionais. Ao passo que Fichte, assumindo o questionamento kantiano, vai porém mais além na sua Kritik, inquirindo sobre os pressupostos racionais em que tais manifestações não-causais podem sequer ser admitidas, e não apenas imediatamente rejeitadas enquanto conhecimento supra-sensível (por conseguinte, numa análise de índole mais reinholdiana, do que kantiana). Mas, sobretudo, interessa salientar que ambas as obras, já num esforço incessante de clarificação das linhas limítrofes entre filosofia e restantes domínios do saber, propõem-se saber como é possível justificar as doutrinas do cristianismo nos limites daquilo que é filosoficamente comprovável - e por conseguinte, daquilo que são os limites da razão humana; isto é, procurava medir-se o princípio da razão em relação à crença, e, se possível, unir Vernunftreligion à dita Offenbarungsreligion. E portanto, este mesmo questionamento, este gesto teórico da Kritik de Fichte pode ser, já por si, discernível como uma primeiríssima forma do que viriam a ser, no decorrer do seu pensamento, os temas propostos também na "Recensão" e nas "Meditações": um questionamento aos limites do conhecimento filosófico, um questionamento à verdadeira forma da filosofia enquanto ciência e, por conseguinte, uma indagação à possibilidade de um princípio absoluto de toda a filosofia.

9 Sobre o tema em questão, não havendo muita, há porém muito importante e interessante bibliografia. Desta destaco: BREAZEALE, D. "Fichte's «Aenesidemus» Review and the Transformation of German Idealism". The Review of Metaphysics, Vol. 34, Nr. 3, pp. 545-568, 1981; BAUM, G. "Aenesidemus oder vom Satz vom Grunde. Eine Studie zur Vorgeschichte der Wissenschaftstheorie". In: Zeitschrift für philosophische Forschung, Bd. 33, H. 3, 1979, pp. 352-370; WOOD, A. W. "Fichte's philosophical revolution". Philosophical Topics, Vol. 19, Nr. 2, Nineteenth-Century Philosophy, pp. 1-28, 1991; DRUET, P.-Ph. "La recension de l'«Énésidème» par Fichte". Revue de Métaphysique et de Morale, 78e Année, Nr. 3, pp. 363-384, 1973; LAUTH, Reinhard. "Genèse du «Fondement de toute la Doctrine de la Science» de Fichte a partir de ses "Méditations personnelles sur l'elementarphilosophie". Archives de Philosophie, Vol. 34, Nr. 1, pp. 5179, 1971; FINCHAM, R. "The Impact of Aenesidemus upon Fichte and Schopenhauer". Pli. The Warwick Journal of Philosophy, 10, pp. 96-126, 2000, entre outras que ou abordam esse mesmo tema, ou o afloram superficialmente. Para um estudo compreensivo do tema, porém, recomendam-se as inevitáveis obras de Henrich (2004, 1. Band) e Frank (1998). 
1) Perceber o papel de Fichte entre Reinhold e Schulze, isto é, a singular dinâmica de aceitação e refutação que na recensão se estabelece com as teorias daqueles, a qual, perante a necessidade de um novo princípio absoluto da filosofia, é levada a suplantar o primeiro devido à influência do segundo, e refutar o segundo por necessidade de suplantar o primeiro;

2) Salientar a importância deste diálogo a três vozes, e sobretudo a voz central de Fichte para a definitiva consolidação da questão da possibilidade de uma filosofia de princípios tal como, para estes, ela fora inaugurada mas também deixada por resolver por Kant;

3) Por fim, não tanto discernir como Fichte chega ao seu princípio da identidade - um trabalho de minúcia que em muito excederia a necessária economia deste pequeno ensaio -, mas antes pensar a possibilidade de este problema poder ser visto por um outro prisma, não apenas enquanto uma questão de filosofia, mas como uma mais relevante questão de linguagem dessa mesma filosofia - assim se estabelecendo uma ponte de sentido entre os problemas levantados na recensão, e o primeiro escrito após esta, "Über den Begriff” (1794).

\section{O enquadramento teórico da "Recensão a Aenesidemus"}

A “Aenesidemus-Rezension” não nasce fortuitamente, e tem por detrás de si um complexo problema de fundo que a suscita, e aí força a junção dos três autores nela implicados. Aliás, o próprio Fichte menciona isto logo no início do escrito, vendo nisso a mola propulsora deste (vd. Fichte, 1794, pp. 3-4). Numa palavra, diremos que esse problema de fundo se baseia originariamente na questão atrás exposta, a que a sua "Kritik aller Offenbarung" não é alheia (nota 8 deste texto), e alcança o seu momento decisivo, já enquanto um problema declaradamente filosófico, na dúvida sobre se é ou não possível consumar a empresa crítica de Kant (e, subsequentemente, se é ou não possivel um princípio absoluto de toda a filosofia).

Esse problema fundamental, embora visível também em Reinhold e Schulze, é porém particularmente sensivel em Fichte. A sua razão de ser é simples; pois, por um lado, Fichte "estava [...] intimamente convicto de que nenhum entendimento humano poderia perseverar para lá do limite em que Kant se encontrara, especialmente na sua Crítica da Faculdade de Julgar $[\ldots] "{ }^{10}$ e portanto, reconhecia que com respeito à faculdade de conhecimento 
- a aquisição das formas das intuições, dos conceitos e das ideias -, a teoria kantiana era insuperável. Mas por outro lado, diria Fichte, se Kant lograra que a cognoscibilidade se universalizasse, ele não lograra porém que esta forma de pensar fosse reconduzida a uma forma superior, mais elementar do conhecimento e da linguagem, a um outro grau de certeza que a comprovasse apodicticamente no espírito humano. Isto é, embora Kant tivesse aventado um princípio absoluto da filosofia, ele não chegara porém a elevá-lo a essa condição (o que, como vimos, se prenunciava já no diálogo em surdina entre "Die Religion innerhalb der Grenzen", de Kant, e a "Kritik aller Offenbarung", de Fichte); e portanto, conclui Fichte, faltara a Kant o corolário da sua empresa: um princípio absoluto da filosofia que unisse os domínios teorético e prático desta $^{11}$ - razão por que um tal sistema não estava ainda consumado. A filosofia não podia elevar-se ainda a um todo sistemático; e por conseguinte, reitera Fichte no início da sua recensão, a filosofia não era ainda uma ciência. ${ }^{12}$

Assim expõe Fichte o problema que subjaz à sua recensão. Mas Fichte, como disse, não fora nem o único, nem o primeiro a sentir este problema.

Reinhold, aliás, tinha sobre este uma opinião em tudo similar, e já desde 1786 o procurava resolver, opondo-se aos supernaturalistas de Tübingen e à propagação de seitas filosóficas adversas a Kant, que então acentuavam este mesmo problema. ${ }^{13} \mathrm{O}$ seu princípio da consciência, exposto, entre outros, nos seus "Beiträge", ${ }^{14}$ dir-se-ia, era a resposta avant la lettre à lacuna apontada por Fichte, visando pois essa mesma instância superior, essa forma mais elementar do conhecimento. Essa instância, diria Reinhold, era o representar, que, segundo o próprio Reinhold, Kant desconsiderara em detrimento do conhecer, assim deixando inacabado o seu edifício crítico. ${ }^{15}$ Pois o representar

Kritik der Urtheilskraft, gestanden [...]" (Fichte, 1794, p. 30) As citações de Fichte, Reinhold e Schulze presentes neste texto são, sem excepção, da minha autoria e responsabilidade. Mas, porque "Über den Begriff" e a "Aenesidemus-Rezension" foram publicadas no mesmo ano (1794), cuidei que, sobretudo ao citar a primeira, menos frequente, esta seja precedida pela designação expressa da obra citada, a fim de evitar confusões com a sua contemporânea "Recensão".

11 Daí que Fichte conclua, em „Über den Begriff”, a respeito da frase da anterior nota: “[...] die er uns aber nie bestimmt, und als die letzte Grenze des enlichen Wissens angegeben hat" (Fichte, 1794, p. 30). A opinião de Fichte, aliás, não só coincidia com a de Reinhold, como seria ainda secundada, por exemplo, por Schelling, em “Über die Möglichkeit einer Form der Philosophie überhaupt” (1794) e „Vom Ich als Princip der Philosophie" (1795), e no texto "Das älteste Systemprogramm des deutschen Idealismus", atribuído a Hölderlin, Schelling ou Hegel.

12 Palavras de Fichte na "Recensão": "[...] dass selbst bis jetzt die Vernunft ihren grossen Zweck, Philosophie als Wissenschaft zu realisiren, noch nicht erreicht haben müsse [...]” (Fichte, 1794, p. 3).

13 Sobre este conflito, que é também a fonte primária do conflito como o expomos em Fichte, vd. as notáveis obras de Henrich (2004, 1. Band), Frank (1998) ou Bondeli (1995).

14 Reinhold (2003, Vol. I).

15 " $\mathrm{Da} \beta$ die Formen der Vorstellungen, so wie sie in der Kritik d. V. aufgestellt werden, auf keinen allgemeingeltenden Grundsatz zurückgeführt sind; und da $\beta$ in diesem Werke von keinem ersten Grundsatze der Wissenschaft des Erkenntnisvermögens, noch weniger von einem ersten Grundsatze der 
é, para Reinhold, anterior ao conhecer; e portanto, o representar, anterior à consciência, e a sujeito e objecto, é para Reinhold género ("Gattung"), ao passo que o conhecer das coisas, posterior à consciência, as espécies ("Arten"); e se a tendência da cognoscibilidade humana tem de ser retroactiva, em direcção a um princípio absoluto de todo o conhecer, isto é, se ela tem de tender das espécies para o género supremo, do conhecer para o representar, então essa progressão tinha de ser ulteriormente determinada por uma forma final (o princípio da consciência) que não só deveria ser conhecida desde o início de tal processo, como forçava o processo a obedecer-lhe sem alguma vez o ultrapassar ou corromper; e da mesma maneira que antes mesmo de se conhecer as espécies já se tem uma representação do género (nesse princípio absoluto), uma tal presciência tinha de se estender desde as suas primeiras até às suas últimas consequências: até à própria essência da filosofia, expressa no próprio acto de filosofar, fazendo a filosofia, até então mera espécie (conhecer), transitar para o seu género mais próximo (o representar), a ciência, e fazendo-a gravitar em torno de um princípio absoluto que unia enfim os domínios teorético e prático da filosofia.

Já Schulze, resoluto opositor deste sistema, mas também do de Tübingen, e tal como Reinhold fiel leitor de Kant, defendia que Kant não culminara a sua teoria com um princípio absoluto simplesmente porque disso não tivera necessidade, na medida em que esse princípio é impossível. A sua posição neste problema era, pois, diametralmente oposta à de Reinhold; e quão oposta, vê-lo-emos de seguida.

Seja como for, uma coisa é certa; Fichte não se quedaria indiferente a estas duas vozes. Pois, por um lado, a proposta de Reinhold muito influenciaria o problema de Fichte como acabámos de o expor, e isso é algo facilmente visível no próprio proceder da filosofia fichteana, e até na própria recensão. Aliás, Fichte sempre fora um leitor atento de Reinhold; e não raras vezes reconhece o quanto a inicial formação do seu sistema devera à filosofia de Reinhold, e ao seu fim de colmatar as lacunas do sistema kantiano. ${ }^{16}$

Philosophie überhaupt, die Rede sei, welcher die Elementarphilosophie unmittelbar und durch dieselbe die von inr abgeleitete theoretische und praktische Philosophie mittelbar begründen soll, weiß jeder Leser derselben" (Reinhold, 1790, pp. 184-185).

16 Entre muitas outras referências, algumas delas até por testemunhos de vozes terceiras, destaco esta pela voz do próprio Fichte, em "Über den Begriff": "Er ist eben so innig überzeugt, dass nach dem genialischen Geiste Kants der Philosophie kein höheres Geschenk gemacht werden konnte, als durch den systematischen Geist Reinholds; und er glaubt den ehrenvollen Platz zu kennen, welchen die ElementarPhilosophie des letzteren bei den weitern Vorschritten, die die Philosophie, an wessen Hand es auch sey, nothwendig machen muss, dennoch immer behaupten wird" (Fichte, 1794, p. 31). 
Mas ao mesmo tempo, não obstante este reconhecimento, não obstante a influência da filosofia elementar sobre si, Fichte afirma que fora antes o estudo de Aenesidemus ${ }^{17}$ que mais decisivamente o influenciara, a ponto de o forçar a uma total destruição e posterior reconstrução do seu próprio edifício de pensamento ${ }^{18}$ - de que, salientamos, a recensão era o primeiro rebento. Pois o facto de que Schulze tivesse escrito Aenesidemus para refutar a filosofia elementar de Reinhold, isso, por si só, deveria naturalmente levantar a oposição de Fichte; tanto mais que Schulze não via nem necessidade nem possibilidade de superar a teoria de Kant, e para ele um princípio absoluto da filosofia era um absurdo. Mas, ao invés, a obra - e sobretudo a maneira como Schulze a dispôs -, lograria criar em Fichte um efeito de distanciação em relação à proposta reinholdiana; e tendo Aenesidemus sido escrita justamente por um dos maiores paladinos contra a filosofia de princípios, e justamente contra um dos maiores paladinos da possibilidade dessa mesma filosofia, isso, mais do que operar uma simples inversão, antes operaria em Fichte uma total revolução espiritual, e obrigá-lo-ia a ver até que ponto seria possível suplantar Reinhold sem porém aderir de tal modo a Schulze que assim negasse a empresa reinholdiana, ou aderisse por completo àquela; e porém, aderir a Schulze de tal modo que guardasse em relação a este distância suficiente para nunca renunciar a Reinhold. Isto é, numa palavra, até que ponto seria possível encontrar um fino, e muito singular meio-termo entre uma refutação de Reinhold que é aceitação de Schulze, e uma refutação de Schulze que é aceitação de Reinhold. Pois, dada a insuficiência de Reinhold e a revolução assim causada em si por Schulze, só esse meio-termo teórico poderia significar para Fichte a via correcta para a prossecução daquele que já então era $o$ móbil primordial da sua doutrina da ciência, a saber, a consumação da faculdade de julgar filosófica, ou, dir-se-ia, a construção de um sistema da razão que abarcasse toda a filosofia, enfim consumando o procedimento crítico de que Kant imbuíra a filosofia em geral.

\section{A incontornável invalidade do princípio da consciência de Reinhold}

Um tal meio-termo, procurá-lo-ia Fichte na “Aenesidemus-Rezension”.

17 Schulze (1911).

18 Vd. Carta a Vloemer, de Novembro de 1793: “[...] dazu kam, daß ich gleich darauf durch die Lectüre eines entschloßnen Skeptikers zu der hellen Ueberzeugung geführt wurde, daß die Philosophie vom Zustand einer Wißenschaft noch weit entfernt sey, u. genöthigt wurde mein eignes bisheriges System aufzugeben, u. auf ein haltbareres zu denken." (in Fichte, Gesamtausgabe, III 2, Nr. 167a, p. 14). Cf. ainda a carta a Flatt, de Novembro ou Dezembro de 1793, in Fichte, Gesamtausgabe, III 2, Nr. 168a, p. 18. 
Aí, sob a aparência de uma simples recensão, Fichte confere ao seu problema fundamental uma forma determinada, in nuce. Para tal, subdivide a sua análise tripartidamente, assim procurando responder às três principais objecções de Schulze em Aenesidemus.

As objecções de Schulze eram: 1) "O princípio da consciência de Reinhold não é uma proposição absolutamente primeira, pois, enquanto proposição e juízo, ela está abaixo da regra suprema de todo o julgar, o princípio da contradição" (Fichte, 1794, p. 5; Schulze, 1792, p. 46); 2) "A proposição da consciência não é uma proposição permanentemente determinada por si própria" (Fichte, 1794, p. 6; Schulze, 1792, p. 48); e 3) "A proposição da consciência não é nem uma proposição universalmente vigente, nem expressa um facto que não esteja associado a uma determinada experiência ou a um certo raciocínio" (Fichte, 1794, p. 6; Schulze, 1792, p. 53). ${ }^{19}$

Ao abordar a primeira objecção, Fichte parte de um pressuposto central em Schulze; a saber, que o princípio da consciência não pode afirmar-se absoluto e, porém, dispensar a validade - essa sim, absoluta - do princípio da contradição; e porque duas posições absolutas não podem coexistir, uma delas, a falsa, teria de ceder, assim revelando a sua não-absolutidade.

O problema, porém, coloca-se em traços mais específicos.

De acordo com Schulze, no seu Aenesidemus, o problema está em que, ao situar-se exclusivamente no domínio teorético, Reinhold eleva aí o princípio da consciência sobre "a regra suprema de todo o julgar", o princípio da contradição. Para o fazer, diz Schulze, Reinhold parte do inegável facto de que o princípio da contradição pode (ou tem de) ser o fundamento ideal ("Ideal Grund"), mas não o fundamento real ("Real Grund") da verdade do princípio da consciência (vd. Schulze, 1792, p. 46); pois este, diz Schulze, "está na experiência" (id., p. 47); e isto é tanto mais certo, quanto também para Schulze o princípio da contradição é teoreticamente supremo, mas subordinado num respeito prático. Mas o que Reinhold faz, diz este, é antes adaptar, fundir os factos que daqui relevam, de tal modo que, a saber, embora numa relação teorética, ao nível da forma, o princípio da consciência tenha de obedecer teoreticamente ao princípio da contradição, que é o seu fundamento ideal (id., p. 47), para Reinhold, ao contrário de Schulze, o princípio da consciência não

19 No original alemão de Fichte: "1) Dieser Satz sey kein absolut erster Satz; denn er stehe als Satz und Urtheil unter der höchsten Regel alles Urtheilens, dem Satze des Widerspruchs.”; "2) Der Satz des Bewusstseyns sey kein durchgängig durch sich selbst bestimmter Satz."; "3) [Endlich sey] der Satz des Bewusstseyns weder ein allgemein geltender Satz, noch drückte er ein Factum aus, das an keine bestimmte Erfahrung und an kein gewissen Raisonnement gebunden sey." Destas, e por motivos de concisão, tratarei apenas as duas primeiras, por me parecer que em certa medida elas esclarecem já a terceira dúvida. 
tem o seu fundamento real na experiência, mas sim em si próprio (mediante a assumpção invertida de que o género é precedente, e as espécies posteriores); e porque não o tem, então o real é também ideal, o que significa que esse princípio não está subordinado a nada, não há nenhum princípio que lhe seja superior e, por isso, ele não tem de obedecer ao princípio da contradição, e é teoreticamente absoluto; e por outro lado, porque o princípio da contradição não pode agir sobre a matéria do princípio da consciência (o que Schulze reconhecia), então para Reinhold isso mesmo é a prova de que o princípio da contradição não pode ser o fundamento ideal do da consciência, e que assim sendo, o princípio da consciência é também absoluto num respeito prático.

Assim, para Schulze, uma tal união não decorria senão de uma confusão deliberada dos dois domínios, de uma mistura das valências de fundamento ideal e fundamento real, visando exclusivamente a obediência a um princípio supremo. Isto é, num esforço de afirmar o seu princípio como absoluto, e a nada o subordinar, Reinhold acabaria por amalgamar a matéria e a forma do princípio da consciência, e afirmar por isso que não só num respeito prático, mas nem mesmo teoreticamente o princípio da consciência tem de obedecer ao da contradição - o que, para Schulze, era o mesmo que confundir os fundamentos lógico e real do princípio, e, pior ainda, erigir o princípio da consciência no seio de um primado teorético da razão, e não no seio de uma saudável coexistência entre teorético e prático.

Mas, para Schulze, uma segunda consequência, mais grave, era óbvia. Pois, por certo, a afirmação do absoluto teorético do novo princípio da consciência era para Schulze um erro; e ao assim erigir o princípio da consciência à condição de princípio teoreticamente absoluto, o que Reinhold fizera fora desinsuflar o lógico de toda a sua logicidade, ou, se quisermos, de toda a sua validade enquanto tal, em detrimento da realidade efectiva do princípio da consciência. Isto é, Reinhold desprovera o princípio da contradição e a sua existência lógica de toda a validade real que ele pretendesse ter no domínio teorético, concedendo-lhe aí uma validade puramente formal e lógica - e porque não podem existir dois absolutos, atribuíra toda a validade real ao princípio da consciência, e reservara a vigência do princípio da contradição a uma ilusória, inexistente logicidade. Mas, aduz Schulze, ao assim distinguir lógico e real, isto não era sem profundas consequências para o sistema de Reinhold. Pois, ao assim proceder, Reinhold estava ao invés a desguarnecer o seu próprio sistema, expondo-o a ataques externos; Reinhold estava, no fundo, a desprover o seu sistema de qualquer impedimento de contacto com o seu (possível) contrário, permitindo assim que um sistema tido como apodíctico entrasse em contacto com a experiência (impedido que estava 
o princípio da contradição de agir sobre ele), o que conduzia esse sistema a múltiplas inconsistências e, em última instância, a um contacto indevido entre logicidade e realidade. E este sim, é, para Schulze, o porquê de não poder o princípio da contradição ser negado; pois o princípio absoluto tem uma relação estreita com todos os outros princípios que compõem o sistema, ligação essa que tem de ser preservada se é que ela não deve ferir a ordem do todo ao progredir analiticamente das espécies para o género. Ora, na ausência do princípio da contradição, a mínima oscilação interpretativa de um termo do sistema resultaria na queda do todo; pois o sistema existe somente de $\mathrm{um}$ determinado modo (o absoluto), não podendo simultaneamente não existir, ou assumir uma outra forma simultânea. E por isso, diz Schulze, o princípio da contradição não pode ser desrespeitado ao nível da forma: pois o fundamento real da verdade de um princípio reside na experiência (Schulze, 1792, pp. 47, 65, etc.), e a sua forma - a sua dimensão lógica - deve obedecer a tal princípio superior.

Voltando à "Recensão a Aenesidemus", e considerando agora como Fichte veria esta troca de argumentos, reitero que ela revelar-se-ia fulcral para Fichte, e isso de um modo duplo, apenas aparentemente contraditório:

primeiro, Fichte concorda com Schulze que, uma vez no domínio teorético, é logicamente impossível ao pensamento ir mais além do que o princípio da contradição, e que é este que determina logicamente a relação entre sujeito e objecto, a forma do princípio da consciência ${ }^{20}$ Fichte (1794, pp. 7-8);

segundo, Fichte afirma porém que, apesar deste erro, um mérito havia a encontrar em Reinhold: que, ao contrário do que Schulze afirmava, Reinhold distinguira de facto entre lógico e real (Fichte, 1794, p. 5); e que a sua única falha estivera na escolha do plano em que resolvera situar esta distinção, e por conseguinte na dimensão que utilizara para promover uma tal distinção: o domínio (exclusivamente) teorético.

Numa palavra, a tese principal de Fichte é que há por certo uma maneira de pensar o princípio da consciência como um princípio regendo-se por leis próprias, e até mesmo como supremo num respeito meramente teorético; mas que, à excepção desta maneira, visto o problema no seu todo, o princípio da consciência não pode suplantar o princípio da contradição sem consequências nocivas para um sistema que se queira apodíctico.

Assim, diz Fichte, são vários os méritos da filosofia elementar de Reinhold - e isso, especialmente num respeito meramente teorético. Pois, para Fichte, unter dem logischen Satze des Widerspruchs, so wie jede mögliche Reflexion" (Fichte, 1794, p. 5). 
importante é que no pensar da questão até aqui, até este respeito teorético, Reinhold tenha seguido o incontornável preceito segundo o qual a reflexão, o único veículo possível desta suplantação no teorético, não é nem meramente lógica, nem meramente real; pois, no acto de pensar, idealidade e realidade têm de se ligar de alguma forma, alcançando assim uma união onde um é o outro - e num respeito teorético, é este mesmo preceito que rege sobre qualquer regra lógica ou real, e é horizonte destas. Aliás, isto mesmo di-lo o próprio Fichte: a saber, que se pressupusermos que é lei incontornável do pensamento pensar segundo o próprio pensamento, isto é, pensar que o pensamento tem de unir em si a idealidade e a realidade de si próprio, então necessário é também que pensemos o princípio absoluto num respeito teorético não de acordo com umas quaisquer regras, mas de acordo com essas mesmas regras; ${ }^{21}$ e portanto, o que isto significa é que, tal como acontece no pensar, que lhe dá origem, as regras lógicas de um qualquer princípio são também, no domínio teorético, as suas regras materiais, ${ }^{22} \mathrm{e}$ isto aplica-se até ao supremo princípio teorético, para o qual a idealidade é com efeito realidade, sem prejuízo de nenhuns dos necessários aspectos apodícticos que Schulze a isto apontara. Isto, reitera porém Fichte, pelo menos num respeito teorético.

Mas o problema está, para Fichte, justamente fora desse respeito - e é aí que para este termina o mérito de Reinhold, e começa o de Schulze. Pois ainda que isto fosse afirmado, um supremo princípio teorético, onde ideal é real, e onde o pensar se rege de acordo com as suas próprias regras, como o defende Reinhold, não é ainda porém um princípio absoluto de toda a filosofia - e isso ainda e sempre devido à influência do princípio da contradição num respeito teorético; e ainda que, para Fichte, uma vez extremado o pensamento de Reinhold, o princípio da contradição até possa ser visto como teoreticamente superior ao da contradição - como se demonstrará já de seguida -, o facto de que a realidade do pensar seja teoreticamente também a sua idealidade não faz ainda, por si só, que um princípio seja teoreticamente e praticamente, antes apenas, quando muito, teoreticamente absoluto. Pois, convenhamos, o que para Fichte é impossível - e importante provar - não é propriamente que a reflexão vá mais além do que o princípio da contradição, mas sim - e aqui reside para ele o erro de Reinhold - que essa suplantação se dê de maneira meramente lógica, e, sobretudo, apenas num respeito teorético. Sim, pois nem

21 "[...] man könne über die Gesetze des Denkens doch nicht anders denken, als nach diesen Gesetzen" (Fichte, 1794, p. 5).

22 "Da aber das dadurch Begründete nur als Gedanke existirt, so solle man der logische Grund eines Gedankens sey zugleich der Real- oder Existential-Grund dieses Gedankens" (Fichte, 1794, p. 13). 
a ultrapassagem se dá para Fichte logicamente (pois, num respeito lógico, o princípio da contradição é supremo e ordena sobre o da contradição, e só ao nível da matéria não pode agir sobre este),${ }^{23}$ nem para ele esta consideração da superioridade da dimensão material do princípio da consciência poderia vir a realizar-se num domínio teorético, mas sim e apenas no prático ${ }^{24}$ (não no "blosse Thatsache", mas sim na "Thathandlung" (Fichte, 1794, p. 8) e sob uma outra forma. E portanto, urgia isso sim que ideal e real fossem agora distinguidos - por certo como defendia Schulze -, mas não para que o princípio da contradição fosse deixado supremo no domínio teorético, ou para que não se procurasse outro para o prático, como era pretensão deste, antes para que assim se constatasse a necessidade de um princípio que fosse senhor de ambos os domínios (fim da futura doutrina da ciência).

Ora, são dois, os importantes ensejos que são extraídos desta posição de Fichte na sua "Recensão a Aenesidemus".

O primeiro, é que a suplantação do princípio da contradição num respeito teorético não se dá apenas - ou não se dá de todo - logicamente. Bem pelo contrário, em vista de que o princípio da contradição não pode agir sobre a materialidade do princípio da consciência, por estar este além da sua jurisdição, e de que o princípio da consciência é, a um tempo, o seu próprio fundamento lógico (por não haver para este pensar uma outra forma que não a da pura realidade), então, conclui Fichte, estas são provas suficientes de que $o$ princípio da consciência não pode suplantar teoreticamente o da contradição senão impondo-lhe a sua materialidade - o que só acontece através da referida materialização do pensar, isto é, da materialização da idealidade de si próprio do pensar. E portanto, num respeito meramente lógico, o princípio da contradição até será teoreticamente inultrapassável; mas se, como o propõe Fichte, se pensasse que a idealidade é realidade (e a esta se subordina), então o princípio da consciência deveria ser materialmente (material + idealmente) considerado, e se assim fosse, o princípio da consciência de Reinhold seria por certo o princípio supremo de toda a filosofia no domínio teorético; e então, num respeito teorético, não num prático, seria também logicamente supremo. ${ }^{25}$

23 "Die Reflexion über den Satz des Bewusstseyns steht ihrer Form nach unter dem logischen Satze des Widerspruchs, so wie jede mögliche Reflexion; aber die Materie dieses Satzes wird durch ihn nicht bestimmt" (Fichte, 1794, p. 5).

24 Sobre este "Primat der praktischen Vernunft über die theoretische" (Fichte, 1794, p. 22), ele vem já como resultado comum do inicialmente referido diálogo entre Die Reigion innerhalb der Grenzen der bloßen Vernunft, de Kant, e a Kritik aller Offenbarung, de Fichte. Sobre este ponto, cf. Henrich (2004, pp. 775-805).

25 "Reinholds Ich stelle mir vor ist das erste der Theoretischen Philosophie." Vd. Fuchs, Lauth e Schieche (1978, p. 68). 
Mas o segundo ensejo, que decorre do primeiro, vai mais além do que este. Pois, com efeito, o princípio da contradição é para Reinhold inferior ao da consciência; e para Fichte de certo modo também, mas, como se viu, apenas considerado teoreticamente, logicamente, não ainda praticamente, sem o que, para Fichte, nenhum princípio verdadeiramente poderia ligar teorético e prático, e afirmar-se absoluto. E porquê? Porque, justamente, só num respeito prático, e apenas num respeito prático, é possível suplantar o princípio da contradição - e não apenas pela amálgama de real e ideal, num respeito teorético. Ou antes: só um princípio que fosse praticamente superior ao princípio da contradição o poderia ser também, de modo inequívoco, teoreticamente - e nunca um que, assim extremado, o pudesse suplantar teoreticamente, mas apenas para se quedar sem validade no prático. E portanto, diria Fichte, não só na proposta de Reinhold, mas nem mesmo na sua própria anterior proposta se poderia ainda afirmar que idealidade e realidade estivessem de facto relacionadas, ou que se deixasse ver já um princípio teoreticamente e praticamente absoluto; e se a referida fusão fichteana entre lógico e material tem de ser vista já, apesar de tudo, como um superior esforço de pensar a questão teoreticamente, porém, ela é também a derradeira comprovação da inépcia prática do princípio da consciência, e a incontornabilidade do princípio da contradição continuava a ser um aviso à necessidade de transferir a resolução da questão para uma outra esfera. Fichte percebia assim, pois, a necessidade de tornar real um pensamento que, na sua dimensão teorética, é apenas pura reflexão; e para si, urgia agora procurar na génese do pensar em geral a explicação tanto da impossibilidade de resolução do problema no teorético, como da necessidade da sua ulterior resolução numa outra esfera: a esfera do prático. Pois, para Fichte, apenas aí, na transição entre teorético e prático, se deve estabelecer a distinção entre lógico e real; e se no teorético lógico e real são um só, então é no prático que deve ocorrer a dissociação, e posterior reunião de ambos; pois se é função do prático reconstituir os passos do teorético, a fim de o legitimar, ${ }^{26}$ então a distinção entre lógico e real tem de reactivar uma tal ligação entre ambos.

Assim, o que isto por fim significava é que, justamente como Fichte, também Reinhold cristalizara o processo de reflexão num pensar que dita leis a si próprio, isto é, num círculo infalível cuja logicidade é também a sua realidade; e isto era, admite Fichte, a consumação da dimensão teorética

26 "[...] ferner, wie durch die Vorstellung dieses an sich hyperphysischen Strebens durch das intelligente Ich, im Absteigen über die Stufen, über welche man in der theoretischen Philosophie aufsteigen muss, eine praktische Philosophie entstehe, ist hier der Ort nicht, zu zeigen" (Fichte, 1794, p. 23). 
da filosofia, por razões atrás aduzidas. Mas se assim era, diz Fichte, por outro lado, ao se fechar sobre si própria na sua total inexpugnabilidade, a absolutização deste princípio tinha de sacrificar uma outra coisa: a sua possível transição para o domínio do prático, o que nestes moldes logo o desregularia, conduzindo-o às oscilações interpretativas de que fala Schulze, e com as quais Fichte se vê forçado a concordar. Isto é, o problema estava em que, ao se absolutizar no teorético, o princípio da consciência também aí se fechava permanentemente; ele tornava-se aí cativo de si próprio, daquilo que aí pretensamente o tornara absoluto (a ligação ideal-real), e sem o que, noutro domínio, seria apenas relativo, a ponto de o seu trânsito para o domínio prático ser impossivel. Fazê-lo (isto é, transitar com este princípio para o domínio prático) envolveria, por conseguinte, uma de duas (im-)possibilidades: ou renunciar à reflexão, ou impô-la à lei de um primado teorético da razão. Mas a resposta a este pequeno (e falso) dilema é para Fichte tão óbvia que, ao assumir a supremacia do princípio da consciência no teorético, Fichte retiralhe já, a um tempo, o carácter de verdadeira absolutidade no plano prático, e nisso distancia-se definitivamente de Reinhold, mas também de Schulze. Ao invés, pressupunha-se por um lado que o novo princípio, embora forjado no teorético, sempre teria de visar o prático; e, por outro, que um novo princípio sempre teria de renunciar a um primado exclusivamente teorético da razão (onde não poderia deixar de confinar com o empírico), ${ }^{27}$ mas que não poderia deixar de partir dele em direcção ao prático. O mesmo é dizer, pois, que havia que pensar algo que transcendesse as meras leis da reflexão, que ultrapassasse a pura especulação: algo que reconsiderasse o domínio do teorético, o superasse e transitasse para o prático: algo para lá do princípio da consciência.

\section{O problema final de Reinhold enquanto um problema de linguagem. A necessária possibilidade de um princípio da identidade}

A decisiva acentuação deste problema e impulso para o que viria a ser a Doutrina da Ciência, a saber, a invalidez do princípio da consciência e subsequente necessidade de um outro princípio supremo da filosofia, surgem na abordagem de Fichte à segunda objecção de Schulze (com a qual Fichte concordaria, mas cuja resolução o afastaria também deste e para sempre marcaria a sua futura filosofia). empirische Selbsbeobachtung, und sagt allerdings eine Abstraction aus" (Fichte, 1794, p. 8). 
No encadeamento da "Aenesidemus-Rezension", esta segunda dúvida surge na esteira da primeira, e reza: "o princípio da consciência não é uma proposição permanentemente determinada por si própria” (Fichte, 1794, p. 6), isto é, uma proposição absolutamente autónoma e necessária.

Pois, diz Schulze, a eficácia de um princípio repousa sobre a reflexão dedicada ao significado dos conceitos que o compõem, a saber, daquilo que, para Reinhold, são as acções fundamentais do princípio da consciência: $o$ diferenciar e o referir. ${ }^{28} \mathrm{E}$ assim era, com efeito; pois, para Reinhold, diferenciar e referir são o veículo relacional dos próprios conceitos no seio do todo sistemático da filosofia: são eles, pois, o próprio meio de comunicação, os termos que ligam género e espécies, o princípio supremo e as subsequentes partes do todo; e portanto, de diferenciar e referir não se exige senão que sejam maximamente apodícticos, a bem de uma perfeita comunicação no seio do sistema. Até porque, reitero, no seio de uma filosofia crítica, a eficácia de tais relações, por actuar directamente sobre o espírito, tem de depositar toda a sua eficácia sobre a própria comunicabilidade dessas relações: dir-seia, pois, numa linguagem apodíctica, científica entre os componentes do todo (Reinhold, 1790, pp. 241-2); de outro modo, "diferenciar" e "referir" seriam meras palavras, não o desejado meio-termo entre palavra e acção, entre logicidade e realidade e, como tal, a prova de leis que não se regem senão de acordo consigo próprias.

Mas se, para Reinhold, o seu princípio era teoreticamente superior ao princípio da contradição, então, conclui Schulze, ele prescindia dessa mesma vigência, e assim perdia-se o rasto do que deveria ser um princípio materialmente apodíctico, justamente devido à possível incorrecta determinação dos conceitos que comporão esse mesmo princípio; e portanto, para Schulze, não só o princípio da consciência não poderia ser superior ao da contradição, como, justamente por isso, a reflexão gerada pelo significado dos conceitos que compõem o conceito de consciência (se livre do da contradição) tão-pouco poderia ser apodíctica.

Ora, segundo vejo a questão - e assim a veria também Fichte na sua "Recensão" -, o problema de Schulze com Reinhold passava a ter contornos mais profundos.

Pois o que estava aqui em questão não mais era apenas a absolutidade ou não do princípio da consciência, antes a causa primeira disso mesmo, a saber, a muito mais grave noção de que era impossível que o princípio da consciência 
de Reinhold se coadunasse, isto é, se fizesse comunicar correctamente às suas partes. Pois se o princípio da contradição é teoreticamente inferior ao da consciência, então também os conceitos de diferenciar e referir de Reinhold não podem ser apodícticos, na medida em que, ao não serem regulados pelo princípio da contradição, então eles não têm para todos os homens o mesmo significado, antes podem conter insuficientes ou excessivas características (Schulze, 1792, pp. 53-55). Para Schulze e Fichte, aqui unos, diferenciar e referir não são pois senão termos ocos e, como tal, uma invenção da subjectividade humana visando trasvestir o fundamento real da coisa mediante o seu fundamento lógico; e por conseguinte, também a relação comunicacional entre sujeito e objecto, até aqui dependente de tais conceitos, vê-se deturpada no seio da consciência, pois todos os conceitos anteriores e posteriores aos de diferenciar e referir - a representação pura e empírica, o sujeito puro e empírico, o objecto puro e empírico - oscilavam agora face à perspectiva de que o sistema pudesse ter várias interpretações, de que o princípio em questão não fosse absoluto isto é, de que a filosofia não era ainda ciência. E se assim é, então - e este é o ponto central da crítica fichteana a Reinhold - poder-se-á dizer que a objecção de Schulze, e a subsequente crítica de Fichte a Reinhold fixavam-se no âmago da teoria deste último, isto é, no justo ponto em que esta fazia assentar a sua força e o seu destino enquanto tal: na determinação retroactiva dos conceitos de género e de espécies e, por conseguinte, na impossibilidade de a correcta ordenação desses conceitos culminar na ascensão do pensamento a um princípio supremo de toda a faculdade de julgar filosófica, reinando, ele próprio, sobre todas as relações entre as partes no todo; numa palavra, $n a$ impossibilidade de uma linguagem puramente crítica, que reunisse todas as outras em si e não deixasse lugar à dúvida e ao erro. ${ }^{29}$

Isto é - e para resumir tudo a uma palavra -, Schulze (e Fichte) aludiam à forte possibilidade de Reinhold cometer aqui o derradeiro pecado filosófico: a saber, de o conteúdo do conceito crítico não ser consentâneo com a forma do seu conceito, ou de a linguagem da filosofia de Reinhold contactar com a experiência, e por conseguinte de não estar a filosofia deste à altura da vida, cuja forma ela pretendia assumir (não logrando, pois, transitar do teorético

29 Uma sentença de morte que Fichte prenuncia logo no início da "Recensão", com as palavras "Wie nun, wenn eben die Unbestimmtheit und Unbestimmbarkeit dieser Begriffe auf einen aufzuforchenden höhern Grundsatz, auf eine reale Gültigkeit des Satzes der Identität und der Gegensetzung hindeutete; und wenn der Begriff des Unterscheidens und des Beziehens sich nur durch die der Identität und des Gegentheils bestimmen liesse?" (Fichte, 1794, p. 6), e que conclui do seguinte modo: “[...] ein Vorstellungs-Vermögen, welches nicht nach den Grundsätzen der Identität und des Widerspruchs urtheilte, ist für uns gar nicht denkbar [...]" (Fichte, 1794, p. 16). 
para o prático). E se, por certo, a crítica de Schulze terminava por aqui; pois, para Schulze, isto era a prova de que o princípio de Reinhold não era absoluto, e não podia existir um tal princípio, já para Fichte, que justamente almejava esse propósito, esta incongruência, enquanto problema de linguagem, significava algo ainda mais decisivo e que definitivamente o aparta daquele; pois, para Fichte, isto, mais do que uma tal prova, era antes uma insuficiência a suprir pela reflexão no seu caminho em direcção ao princípio que Schulze negava.

Pois, por certo, os conceitos de sujeito, objecto e representação (no seu diferenciar e referir-se recíprocos) residem efectivamente na consciência, "e a proposição que a estabelece [é], enquanto proposição reflexiva, de acordo com a sua validade lógica, uma proposição analítica" (Fichte, 1794, p. 7); ${ }^{30} \mathrm{e}$ nisto, Fichte concorda com Reinhold. Mas se este mesmo grau de analiticidade estava ancorado numa linguagem inconstante, arbitrária, então esta, em vez de ser prova de apodicticidade, revelava-se agora justamente o último obstáculo à obtenção de um suplemento não-reflexivo indispensável a um princípio absoluto, e a uma elevação da filosofia a ciência. E por conseguinte, diz Fichte, este suplemento só seria possível na medida em que "a acção do próprio representar, o acto da consciência [fosse] manifestamente uma síntese" (id.); $;^{31}$ o que, por sua vez, apenas poderia significar que, para Fichte, Reinhold por certo levara a filosofia ao máximo da sua analiticidade, mas não ainda da sua reflexividade, e que, enquanto tal, enquanto proposição primeira do domínio teorético que era, o princípio da consciência corresponde, nas suas relações com o todo do sistema, ao máximo de comunicabilidade teorética: mas para uma sua transição para o prático, era necessário ainda um outro grau, uma outra forma de comunicabilidade (sintética), uma outra linguagem filosófica, só possível na sua total originariedade de reflexão primeira. E por fim, se já Reinhold visara com a sua analiticidade absoluta uma linguagem absoluta, também Fichte, ao visar corrigir os contornos e os limites dessa mesma analiticidade, teria de vir a inscrever esse esforço na procura do mesmo objectivo; o que no fundo significava que a união entre analítico e teorético proposta por Fichte, bem como o princípio da identidade absoluta (a doutrina da ciência), implicariam um derradeiro esforço na aquisição de uma linguagem totalmente sistemática e apodíctica, sem as incongruências a que a de Reinhold estava exposta.

30 "[...] und der Satz, der sie aufstellt, ist als Reflexions-Satz, seiner logischen Gültigkeit nach, allerdings ein analytischer Satz" (Fichte, 1794, p. 7).

31 "[...] Aber die Handlung des Vorstellens selbst, der Act des Bewusstseyns, ist doch offenbar eine Synthesis, da dabei unterschieden und bezogen wird; und zwar die höchste Synthesis, und der Grund aller möglichen übrigen" (Fichte, 1794, p. 7). 
Um tal esforço, e um tal problema, por si só motivos para um outro ensaio, viria Fichte a retomá-los na obra imediatamente subsequente a esta, "Über den Begriff der Wissenschaftslehre" (1794), e no ensaio "Von der Sprachfähigkeit und dem Ursprung der Sprache" (1795), a conjunção dos quais por fim comprova que a doutrina da ciência, todo o sistema do pensamento de Fichte tinham como destinação serem elevados à condição de terminologia sistemática da filosofia, e esta, por sua vez, à condição de um sistema apodíctico, uma dupla cristalização que visava a consumação da faculdade de julgar filosófica.

\section{Referências}

BONDELI, M. "Das Anfangsproblem bei Karl Leonhard Reinhold. Eine systematische und entwicklungsgeschichtliche Untersuchung zur Philosophie Reinholds in der Zeit von 1789 bis 1803". Frankfurt: Klostermann, 1995.

BREAZEALE, D. "Thinking Through the Wissenschaftslehre: Themes from Fichte's Early Philosophy”. Oxford: Oxford University Press, 2013.

FICHTE, J. G. "Gesamtausgabe der Bayerischen Akademie der Wissenschaften". Hg. von Reinhard Lauth u. Hans Jakob, Stuttgart-Bad Cannstatt: Frommann-Holzboog, 1962-2012.

. "Fichtes Werke" (11 Bde.). Hg. Immanuel Hermann Fichte. Berlin: Walter de Gruyter, 1971.

FRANK, M. “`Unendliche Annäherung〈. Die Anfänge der philosophischen Frühromantik". Frankfurt am Main: Suhrkamp, 1998.

FUCHS, E., LAUTH, R., SCHIECHE, W. "Fichte im Gespräch" (6 Bde.). StuttgartBad Cannstatt: Frommann-Holzboog, 1978.

HENRICH, D. "Grundlegung aus dem Ich. Untersuchungen zur Vorgeschichte des Idealismus". Tübingen - Jena (1790-1794), 2 Bde. Darmstadt: Wissenschaftliche Buchgesellschaft, 2004.

JANKE, W. "Vom Bilde des Absoluten: Grundzüge der Phänomenologie Fichtes". Berlin, New York: De Gruyter, 1993.

MARTIN, W. M. "Idealism and Objectivity: Understanding Fichte's Jena Project". Stanford: Stanford University Press, 1997.

REINHOLD, K. L. (1790) "Beiträge zur Berichtigung bisheriger Missverständnisse der Philosophen" (2 Bde.). Hg. von Faustino Fabianelli. Hamburg: Felix Meiner Verlag, 2003.

SCHULZE, G. E. (1792). "Aenesidemus oder über die Fundamente der von dem Herrn Professor Reinhold in Jena gelieferten Elementar-Philosophie”. Hg. von KantGesellschaft. Berlin: Reuther \& Reichard, 1911.

SCHWABE, U. "Individuelles und Transindividuelles Ich. Die Selbstindividutation reiner Subjectivität und Fichtes Wissenschaftslehre". Paderborn: Ferdinand Schöningh, 2007. 